\title{
Características agronômicas, estruturais e bromatológicas do capim Piatã em lotação intermitente com período de descanso variável em função da altura do pasto
}

\author{
Agronomic characteristics, structural and chemical characteristics of grass in Piata \\ stocking with intermittent rest periods vary depending on the sward height
}

\author{
DIM, Valdinéia Patricia ${ }^{1 *}$; ALEXANDRINO, Emerson ${ }^{2}$; SANTOS, Antonio \\ Clementino dos ${ }^{2}$; MENDES, Ronaldo da Silva ${ }^{1}$; SILVA, Darlene Pereira da ${ }^{1}$
}

\author{
${ }^{1}$ Universidade Federal do Tocantins, Escola de Medicina Veterinária e Zootecnia, Programa de Pós- \\ Graduação em Ciência Animal Tropical, Araguaina, Tocantins, Brasil. \\ ${ }^{2}$ Universidade Federal do Tocantins, Escola de Medicina Veterinária e Zootecnia, Departamento de \\ Zootecnia, Araguaina, Tocantins, Brasil. \\ *Endereço para correspondência: valpatdim@hotmail.com
}

\section{RESUMO}

Objetivo-se avaliar a influência das diferentes alturas de pastejo sobre as características agronômicas, estruturais e bromatológicas da Brachiaria brizantha cv. Piatã manejada sob lotação intermitente. Avaliou-se três alturas do dossel forrageiro $(30,45$ e $60 \mathrm{~cm}$ ) ao longo de duas estações de crescimento (Meio e Final da estação). Adotou-se o delineamento em blocos ao acaso, com parcelas subdivididas, onde as parcelas foram alocadas as alturas e nas subparcelas as estações de crescimento. Os valores de altura atenderam o protocolo experimental apresentando médias de 35,$2 ; 43,5$ e 59,4, respectivamente para 30,45 e $60 \mathrm{~cm}$ de altura. O período de descanso foi variável no decorrer das alturas e proporcionou diferentes ciclos de pastejo, com PD médio de 34, 39 e 54 dias, respectivamente, para as alturas estudadas. A maior produtividade de MST obtida por ciclo foi na altura de $60 \mathrm{~cm}$, com média de $4612,51 \mathrm{~kg}$ ha-1 e, $3566 \mathrm{~kg}$ ha-1 para altura de 30 $\mathrm{cm}$. No entanto nas alturas de 30 e $45 \mathrm{~cm}$ foram obtidos três ciclos de pastejo e somente dois para a altura de $60 \mathrm{~cm}$, totalizando com isso, 12,4, 10,7 e 9,2 t MS ha-1 no período. Na relação folha/colmo não houve diferença nas alturas estudadas. O número de perfilho não sofreu alteração com as diferentes alturas, sendo observada a superioridade do número de perfilhos no meio da estação de crescimento. $\mathrm{O}$ aumento na altura do pasto não proporcionou alteração no teor de $\mathrm{PB}$ e na digestibilidade e aumento nos teores de FDA, apenas foi alterado FDN na altura de $60 \mathrm{~cm}$.

Palavras-chave: estrutura do pasto, manejo da pastagem, produção de forragem

\section{SUMMARY}

Objective was to evaluate the influence of different grazing height on agronomic, structural and qualitative characteristics of Brachiaria brizantha cv. Piata managed under rotational stocking. We evaluated three sward heights $(30,45$ and $60 \mathrm{~cm})$ over two growing seasons (Middle and Final Season). We adopted the randomized complete block design with split plot, where the plots were allocated heights and subplots the growing seasons. Height values met the experimental protocol, showing averages of $35.2 ; 43.5$ and 59.4, respectively 30, 45 and 60 $\mathrm{cm}$. The rest period was variable during the heights and providing different grazing cycles, with an average DP of 34, 39 and 54 days, respectively, to the heights studied . The highest yield obtained by MST cycle was at the height of $60 \mathrm{~cm}$, with an average of $4612.51 \mathrm{~kg} \mathrm{ha}^{-1}$ and $3566 \mathrm{~kg} \mathrm{ha}^{-1}$ to $30 \mathrm{~cm}$ height. However the heights of 30 and $45 \mathrm{~cm}$ three cycles of grazing and only two to the height of $60 \mathrm{~cm}$ were obtained, totaling about it, 12.4, 10.7 and $9.2 \mathrm{t}$ $\mathrm{DM} \mathrm{ha}{ }^{-1}$ in the period. In leaf/stem ratio, no differences in heights studied. The number of tillers did not change with different heights, the superiority in the number of tillers was observed in the middle of the growing season. The increase in sward height provided no change in $\mathrm{CP}$ content and digestibility and increased levels of ADF, NDF was changed only at the height of $60 \mathrm{~cm}$.

Keywords: herbage production, pasture management, pasture structure 


\section{INTRODUÇÃO}

Com a expansão da atividade pecuária no país e o aumento na comercialização de carne bovina no mercado externo, torna-se crescente a demanda pela eficiência em produtividade. As pastagens cultivadas já conquistaram destaque no Brasil em substituição às nativas, principalmente devido ao padrão de produção que se firmou nos últimos anos, exigindo cultivares mais produtivos e adaptados (ZIMMER \& EUCLIDES, 2000).

$\mathrm{Na}$ tentativa de mudança do cenário atual a Brachiaria brizantha cv. Piatã surgiu como uma nova opção para a diversificação das espécies forrageiras utilizadas na pastagem, e por ter sido lançada recentemente, existe poucas informações para definir as estratégias de seu manejo no ambiente Amazônico. Neste contexto, pode-se atribuir que o conhecimento do comportamento da planta forrageira submetida a regimes de diferentes alturas de entrada, pode ser de grande importância técnica, tornando possível a melhor utilização do pasto nas condições edafoclimáticas dessa região.

Diante dessa situação, o manejo do pastejo deveria ser contextualizado às estações do ano e a essa localização específica, pois uma única ação de manejo não seria eficiente e/ou vantajosa sob condições abióticas diferentes nas mais diversas regiões do país. $\mathrm{Na}$ verdade, o manejo do pastejo, concebido e idealizado de forma sazonal, consiste em ajuste fino ou aprimoramento das atuais recomendações de manejo, baseadas em valores de alturas médias dos pastos sob lotação intermitente.

Em decorrência da carência de informações sobre o comportamento de tais características do capim Piatã sob pastejo intermitente, realizou-se este trabalho com o objetivo de estudar o efeito das diferentes alturas de corte sobre produção da biomassa de forragem, comportamento estrutural e nutricional em pastagens de Brachiaria brizantha $\mathrm{cv}$. Piatã ao longo da estação de crescimento da forragem.

\section{MATERIAL E MÉTODOS}

O experimento foi conduzido na Universidade Federal do TocantinsUFT, Campus Universitário de Araguaína-TO, na Escola de Medicina Veterinária e Zootecnia, localizado a 07'12'28', Latitude Sul e 48 $12^{\prime} 26^{\prime \prime}$, Longitude Oeste, com altitude de 236 m. O clima da região, segundo a classificação de Köppen (1948) é AW Tropical de verão úmido com estação seca e chuvosa bem definida com período de estiagem no inverno. Apresenta temperaturas máximas de $40^{\circ} \mathrm{C}$ e mínimas de $18^{\circ} \mathrm{C}$, com umidade relativa do ar média anual de $76 \%$.

Os dados das variáveis ambientais foram coletados semanalmente na Estação Agro-meteorológica do Campus Universitário de Araguaína$\mathrm{TO}$, localizado nas proximidades do experimento $(700 \mathrm{~m})$, durante todo $\mathrm{o}$ período experimental (Tabela 1).

O solo da área é classificado como Neossolo Quartzarênico Órtico típico (EMBRAPA, 2006) o qual foi analisado no Laboratório de Solos da UFT, na Escola de Medicina Veterinária e Zootecnia.

A semeadura das forrageiras foi feita a lanço após gradagem da área no início das chuvas da estação de crescimento 2008/2009, em área previamente corrigida e adubada com base na análise do solo. Em maio de 2010, a forragem foi coletada com máquina forrageira e o material armazenado em silos, os quais foram utilizados para confinamento no 
Rev. Bras. Saúde Prod. Anim., Salvador, v.16, n.1, p.10-22 jan./mar., 2015 http://www.rbspa.ufba.br

período de julho a setembro do mesmo ano. A área permaneceu vedada até o mês de outubro de 2010, onde teve início a correção do solo com 1 tonelada $\mathrm{ha}^{-1}$ de calcário $(\mathrm{PRNT}=(98 \%) \mathrm{em}$ superfície, e em seguida, aplicação de dose única de $80 \mathrm{~kg}$ de $\mathrm{P}_{2} \mathrm{O}_{5} \mathrm{ha}^{-1}$ via superfosfato simples em meados de novembro. Em janeiro de 2011 foi feito o corte de uniformização da pastagem, e no início do perfilhamento, foram realizadas duas adubações de cobertura com adubo formulado (20:0:20) na dose de $250 \mathrm{~kg} \mathrm{ha}^{-1}$ ano. Ao longo do período experimental a adubação foi realizada a cada corte, sendo calculado a quantidade de adubo a ser aplicado de acordo com os dias de descanso de cada área e/ou altura sendo, em média, de 1,6 $\mathrm{kg}$ de $\mathrm{Ne} \mathrm{K}_{2} \mathrm{O}$ ha dia ${ }^{-1}$ de rebrotação. $\mathrm{O}$ período experimental teve início em janeiro de 2011 e se estendeu até maio de 2011.

Tabela 1. Valores médios da temperatura, umidade relativa do ar, radiação solar, precipitação pluvial e velocidade do vento nos ciclos e na estação de crescimento (meio e final da estação)

\begin{tabular}{lccccc}
\hline Variáveis & Ciclo1 & Ciclo 2 & Ciclo3 & Meio da estação & Final da estação \\
\hline Altura de 30 cm & & & & & \\
\hline Temp. Média $\left({ }^{\circ} \mathrm{C}\right)$ & 25,9 & 26,6 & 26,4 & 25,9 & 26,5 \\
Umidade(\%) & 85,5 & 86,1 & 84,5 & 85,5 & 85,3 \\
Radiação $(\mathrm{W} / \mathrm{m} 2)$ & 1412,5 & 1482,5 & 1384,2 & 1412,5 & 1433,4 \\
Precipitação (mm) & 287 & 282 & 246 & 282 & 528 \\
Velocidade do vento (m/s) & 0,75 & 0,83 & 0,9 & 0,75 & 0,86 \\
\hline Altura de 45 cm & & & & & 26,4 \\
\hline Temp. Média $\left({ }^{\circ} \mathrm{C}\right)$ & 26,0 & 26,4 & 26,4 & 26,0 & 83,9 \\
Umidade(\%) & 86,7 & 86,6 & 81,1 & 86,7 & 1400,2 \\
Radiação $(\mathrm{W} / \mathrm{m} 2)$ & 1308,7 & 1343,4 & 1457,0 & 1308,7 & 374 \\
Precipitação $(\mathrm{mm})$ & 463 & 280 & 94 & 463 & 0,97 \\
Velocidade do vento (m/s) & 0,8 & 0,8 & 1,15 & 0,8 & 26,8 \\
\hline Altura de 60 cm & & & & & 84,3 \\
\hline Temp. Média $\left({ }^{\circ} \mathrm{C}\right)$ & 26,11 & 26,8 & - & 26,11 & 1466,0 \\
Umidade $(\%)$ & 86,3 & 84,3 & - & 86,3 & 297 \\
Radiação $(\mathrm{W} / \mathrm{m} 2)$ & 1325,3 & 1466,9 & - & 1325,3 & 0,86 \\
Precipitação $(\mathrm{mm})$ & 537 & 297 & - & 537 & \\
Velocidade do vento $(\mathrm{m} / \mathrm{s})$ & 0,76 & 0,86 & - & 0,76 & \\
\hline
\end{tabular}

A área experimental foi de 7,1 hectares, subdividida em duas glebas, sendo alocados dois blocos subdivididos em três piquetes em cada um com 1,18 ha em cada piquete. Os piquetes designados a altura de $30 \mathrm{~cm}$ foram subdivididos em 6 faixas com o auxilio de fitas eletrificadas $\left(1.953,3 \mathrm{~m}^{2}\right)$, os de $45 \mathrm{~cm}$ em $7\left(1.673,6 \mathrm{~m}^{2}\right)$ e os de $60 \mathrm{~cm}$ em 8 faixas $\left(1.464,3 \mathrm{~m}^{2}\right)$, conforme expectativa para o período de descanso (Figura 1).

O delineamento experimental foi em blocos casualizados em esquema de parcelas subdivididas com combinação $3 \times 2$, sendo três alturas do pasto no momento de pré-pastejo $(30 ; 45 ; 60 \mathrm{~cm}$ de altura) e duas estações de crescimento (meio e final), com quatro repetições por tratamento. 
Rev. Bras. Saúde Prod. Anim., Salvador, v.16, n.1, p.10-22 jan./mar., 2015 http://www.rbspa.ufba.br
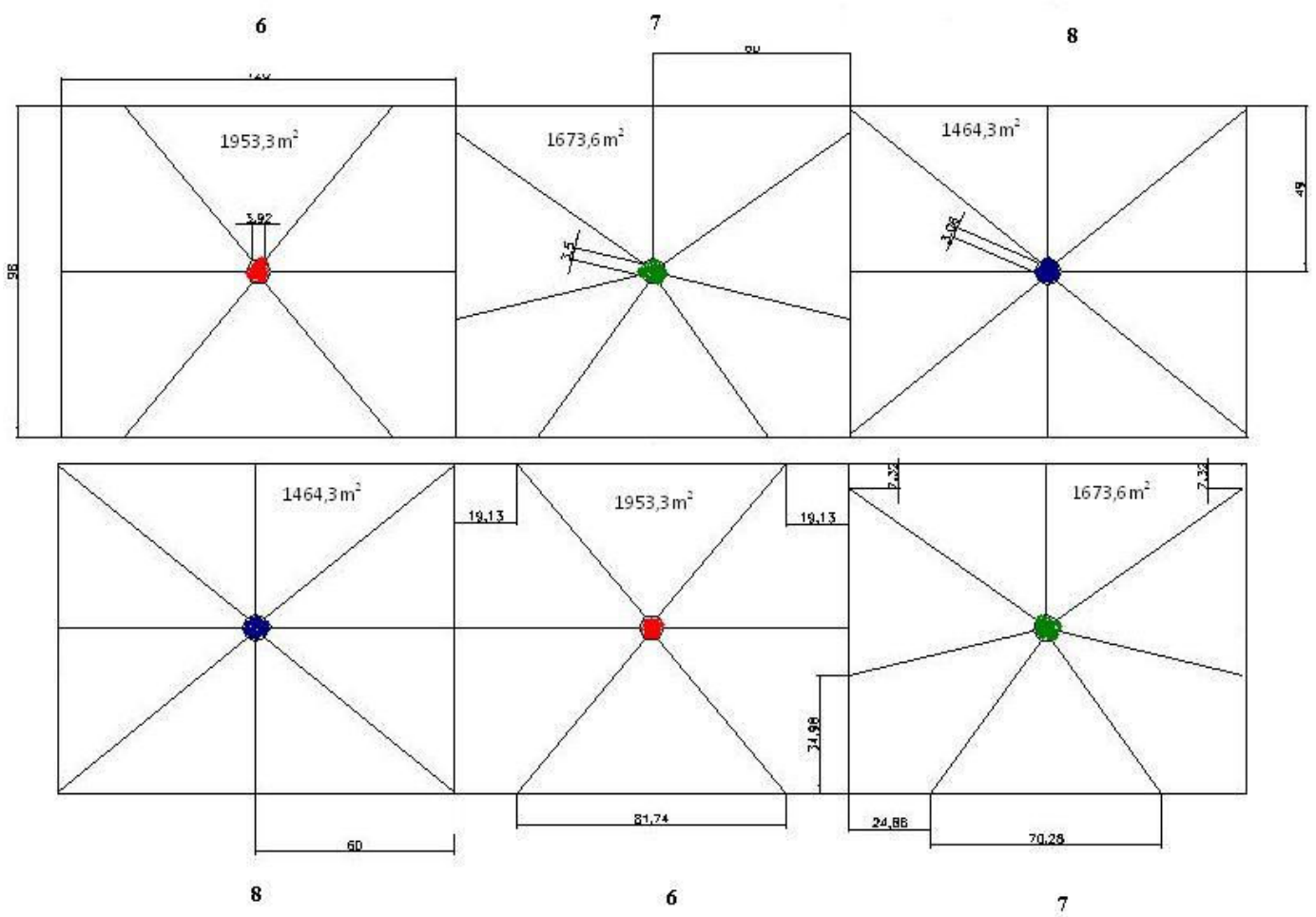

Figura 1. Croqui da divisão da área experimental

A área experimental foi manejada sob lotação intermitente, com taxa de lotação variável, sendo a movimentação dos animais baseada em função da altura do pasto no momento pré e pós-pastejo. As alturas pré-pastejo respeitaram os tratamentos experimentais, e a condição pós-pastejo foi de aproximadamente $50 \%$ da altura inicial.

O monitoramento da altura do pasto foi realizado duas vezes por semana medindo-se com régua graduada 30 pontos aleatórios por piquete, tendo o plano imaginário da altura média da curvatura das folhas como referência da altura do dossel forrageiro.

Para avaliação do número de perfilhos (NP), expresso em perfilhos $\mathrm{m}^{2}$ utilizouse uma área de amostragem de $0,031416 \mathrm{~m}^{2}$ representada por um anel de cano plástico (PVC) de $20 \mathrm{~cm}$ de diâmetro e $5 \mathrm{~cm}$ de altura fixado ao solo, sendo que em cada unidade experimental existiam dois anéis. Cada amostragem foi realizada dentro de um período de oito dias. As gerações de perfilhos foram marcadas com argolas plásticas de cores distintas, sendo que a cada amostragem os perfilhos pertencentes às gerações pré-existentes eram contados e os novos marcados com uma nova cor.

No momento em que a planta atingia a altura de entrada pré-estabelecida (30; 45; 60), eram amostrados dois pontos por parcela, representado pela altura média do dossel forrageiro, e com auxílio de um quadro de amostragem, um retângulo metálico de $0,6 \mathrm{~m}^{2}(1,0 \mathrm{x}$ $0,6)$ a forragem foi colhida à altura de $10 \mathrm{~cm}$ do solo, colocada em sacos previamente identificados, levada a casa de apoio para processamento. $\mathrm{O}$ material foi separado em lâmina foliar, colmo e material morto, pesando-se cada fração separadamente. Em seguida foi seca a $55^{\circ} \mathrm{C}$ por 72 horas a fim de se estimar sua massa seca. A partir desses dados, foi estimada: a biomassa seca 
total, de folhas, de colmo, de material morto e a relação folha/colmo.

Para a avaliação bromatológica do capim Piatã, foi feio uma coleta de forragem simulando o pastejo animal. Este material foi colocado em sacos de papel identificados e seco em estufa à $55^{\circ} \mathrm{C}$ por 72 horas. Após a secagem as amostras foram moídas em moinho do tipo Willey, com peneira de $1 \mathrm{~mm}$, armazenadas em recipientes plásticos e identificadas. Em seguida foram realizadas as análises, no Laboratório de Nutrição Animal da Escola de Medicina Veterinária e Zootecnia, para determinação da proteína bruta $(\mathrm{PB})$, fibra detergente neutro (FDN) e fibra detergente ácida (FDA) e matéria seca (MS), conforme a metodologia de Van Soest (1994).

$O$ índice de área foliar (IAF) foi estimado a partir de uma sub-amostra de lâmina foliar do material colhido. Para isso, uma alíquota das lâminas foliares foi cortada em segmentos de $10 \mathrm{~cm}$, e o somatório da largura média de todos segmentos era multiplicado por $10 \mathrm{~cm}$, estimando-se assim área foliar da subamostra. Os segmentos medidos, em torno de 100, em média, eram pesados a fim de se estimar sua área foliar específica $\left(\mathrm{cm}^{2}\right.$ de lâmina foliar $\mathrm{g}$ de lâmina foliar ${ }^{-1}$ ), a partir da qual e do peso total das lâminas foliares, foi estimado a área foliar correspondente à área do quadro de amostragem $\left(0,6 \mathrm{~m}^{2}\right)$. O IAF $\left(\mathrm{m}^{2}\right.$ de folha $\mathrm{m}^{2}$ de solo $\left.^{-1}\right)$ foi obtido pela divisão da área foliar estimada por $0,6 \mathrm{~m}^{2}$ (ALEXANDRINO et al., 2005).

As análises foram realizadas com auxílio do programa SISVAR Sistema para Análises Estatísticas versão 5.1, onde resultados foram submetidos à análise de variância, e quando significativos $(\mathrm{P}<0,05)$ foi realizada a comparação de médias pelo teste de Tukey a $5 \%$ de probabilidade para os efeitos principais e do desdobramento da interação quando necessário.

\section{RESULTADOS E DISCUSSÃO}

Os pastos tiveram pequenas variações nas alturas pretendidas no decorrer do período estudado, atendendo $\mathrm{o}$ protocolo experimental de forma satisfatória, onde foram obtidas as médias de alturas de 35,$2 ; 43,5$ e 59,4 respectivamente (Figura 2).

De acordo com Gonçalves et al. (2002), o intervalo de corte é uma prática de manejo que contribui para determinar a produção e a qualidade da forragem, sendo que cortes em intervalos menores resultam em baixas produções de matéria seca; no entanto apresenta alta relação folha/colmo, determinando valor nutritivo mais elevado.

Para todas as variáveis, na condição de pós-pastejo verificou-se efeito somente para a altura de manejo (Figura 2), possivelmente em função do controle de saída dos animais das áreas em função do manejo do pastejo.

Certamente, as interações observadas entre altura pré-pastejo e estação de crescimento sobre $\mathrm{o}$ período de descanso (PD) pode estar relacionada às diferentes condições do meio durante os diferentes períodos de rebrotação (Tabela 1).

O período de descanso (PD) foi variável no decorrer das alturas e proporcionou diferentes ciclos de pastejo, sendo três ciclos na altura de 30 e $45 \mathrm{~cm}$ e apenas dois ciclos na altura de $60 \mathrm{~cm}$ ao longo do período experimental, sendo essa resposta variável em função das estações de crescimento. O PD foi variável para todas as alturas de manejo no meio da estação de crescimento, mas no final da estação não observou-se diferença entre as alturas de 30 e $45 \mathrm{~cm}$ (Tabela 2). 


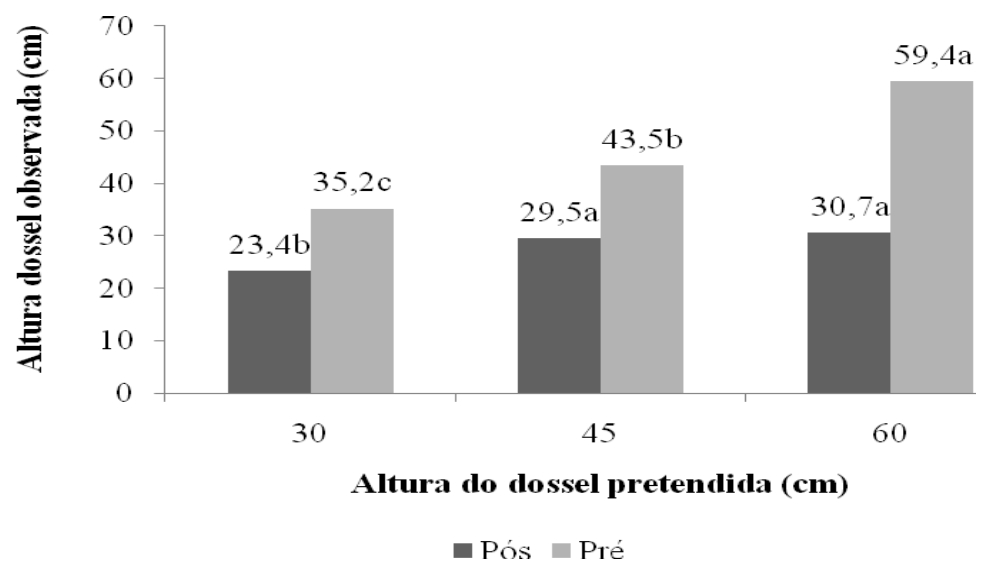

Figura 2. Altura do dossel forrageiro no pós e pré-pastejo do capim Piatã manejado sob lotação intermitente com três alturas de entrada

Tabela 2. Período de descanso (dias) do capim Piatã manejado sob lotação intermitente com três alturas de entrada durante as estações de crescimento (meio e final)

\begin{tabular}{ccccc}
\hline Altura $(\mathrm{cm})$ & Meio da estação & Final da estação & Média & CV $(\%)$ \\
\hline 30 & $36,00^{\mathrm{aC}}$ & $32,00^{\mathrm{aB}}$ & 34,00 & - \\
45 & $46,00^{\mathrm{aB}}$ & $32,00^{\mathrm{bB}}$ & 39,00 & 10,29 \\
60 & $65,50^{\mathrm{aA}}$ & $43,00^{\mathrm{bA}}$ & 54,25 & - \\
\hline Média & 49,17 & 35,67 & 42,42 & - \\
\hline
\end{tabular}

Médias seguidas de letras iguais maiúsculas na coluna e minúsculas na linha iguais não diferem entre si pelo teste Tukey a $5 \%$ de probabilidade de erro.

$\mathrm{CV}=$ coeficiente de variação

A massa seca total de forragem (MST) foi variável em função das alturas avaliadas, mas observou-se resposta diferenciada em função da estação avaliada. $\mathrm{Na}$ avaliação do inicio das chuvas, a massa seca total foi incrementada à medida que elevou a altura do dossel, mas no final da estação não foi observado efeito de altura sobre a MST. Multiplicando-se o número de ciclos pela MST média de cada ciclo, obtem-se que os dosséis forrageiros manejados entre 30 e $45 \mathrm{~cm}$ de altura produziram em média $11,5 \mathrm{t} \mathrm{MS} \mathrm{ha}^{-1}$, ao passo que os de $60 \mathrm{~cm}$ foram $20 \%$ menos produtivos $\left(9,2 \mathrm{t}\right.$ MS ha $\left.{ }^{-1}\right)$. Provavelmente, a menor produção ocasionada nos pastos manejados em maior altura reflete a fase de platô na curva de crescimento sigmóide do capim.

Quando comparado o efeito das estações de crescimento, somente para a altura de $30 \mathrm{~cm}$ foi observado maior produção para o final da estação de crescimento. Provavelmente, essa resposta está relacionada às condições ambientais reinantes em cada estação de crescimento de cada altura de manejo (Tabela 1).

Os componentes morfológicos lâmina foliar e colmo, também sofreram alteração no decorrer das alturas na qual na altura de $60 \mathrm{~cm}$ foi superior somente a altura de $30 \mathrm{~cm}$ (Tabela 3 ), sendo o colmo com a mesma interferência que a MST teve em relação à estação de crescimento estudadas, ou seja, sendo responsiva somente no meio da estação, 
Rev. Bras. Saúde Prod. Anim., Salvador, v.16, n.1, p.10-22 jan./mar., 2015 http://www.rbspa.ufba.br

enquanto em plantas mais altas, os perfilhos são mais compridos e, assim, necessitam de colmo mais espesso e desenvolvido para sustentar seu maior peso. Ademais, é possível que tenha ocorrido competição por luz entre os perfilhos e, como conseqüência, ocorreu o alongamento do colmo para expor as folhas jovens na parte superior do dossel, onde a luz é mais abundante (SILVA \& CORSI, 2003, SILVA et al. 2011).

Tabela 3. Matéria seca total (MST) e dos componentes morfológicos lâmina foliar (MSLF), colmo (MSC) e material morto (MSMM) do capim Piatã no prépastejo manejado sob lotação intermitente com três alturas de entrada durante as estaçãos (meio e final da estação)

\begin{tabular}{|c|c|c|c|c|}
\hline \multirow{2}{*}{$\begin{array}{l}\text { Período } \\
\text { Altura }(\mathrm{cm})\end{array}$} & Meio & Final & \multirow{2}{*}{ Média } & \multirow{2}{*}{ CV $(\%)$} \\
\hline & \multicolumn{2}{|c|}{$\operatorname{MST}\left(\mathrm{kg} \mathrm{ha}^{-1}\right)$} & & \\
\hline 30 & $2957,8^{\mathrm{bB}}$ & $4173,7^{\mathrm{aA}}$ & 3565,7 & - \\
\hline 45 & $3803,9^{\mathrm{aAB}}$ & $4435,4^{\mathrm{aA}}$ & 4119,7 & 19,36 \\
\hline 60 & $4413,8^{\mathrm{aA}}$ & $4811,2^{\mathrm{aA}}$ & 4612,5 & - \\
\hline \multirow[t]{2}{*}{ Média } & 3725,2 & 4473,4 & 4099,3 & - \\
\hline & \multicolumn{2}{|c|}{$\operatorname{MSLF}\left(\mathrm{kg} \mathrm{ha}^{-1}\right)$} & & \\
\hline 30 & $1749,4^{\mathrm{bB}}$ & $2308,6^{\mathrm{aB}}$ & 2028,9 & - \\
\hline 45 & $2297,2^{\mathrm{aAB}}$ & $2104,3^{\mathrm{aAB}}$ & 2200,7 & 17,49 \\
\hline 60 & $2619,0^{\mathrm{aA}}$ & $2750,6^{\mathrm{aA}}$ & 2684,8 & - \\
\hline Média & 2221,8 & 2387,8 & 2304,8 & - \\
\hline Altura & \multicolumn{2}{|c|}{$\operatorname{MSC}\left(\mathrm{kg} \mathrm{ha}^{-1}\right)$} & & \\
\hline 30 & $716,5^{\mathrm{bB}}$ & $1155,8^{\mathrm{aA}}$ & 936,2 & - \\
\hline 45 & $1091,5^{\mathrm{bAB}}$ & $1497,7^{\mathrm{aA}}$ & 1294,6 & 23,47 \\
\hline 60 & $1334,1^{\mathrm{aA}}$ & $1503,6^{\mathrm{aA}}$ & 1418,8 & \\
\hline \multirow[t]{2}{*}{ Média } & 1047,4 & 1385,7 & 1216,5 & - \\
\hline & \multicolumn{2}{|c|}{$\operatorname{MSMM}\left(\mathrm{kg} \mathrm{ha}^{-1}\right)$} & & \\
\hline 30 & $491,8^{\mathrm{aA}}$ & $709,3^{\mathrm{aA}}$ & 600,6 & - \\
\hline 45 & $415,2^{\mathrm{bA}}$ & $833,3^{\mathrm{aA}}$ & 624,2 & 34,07 \\
\hline 60 & $460,7^{\mathrm{aA}}$ & $556,9^{\mathrm{aA}}$ & 508,8 & - \\
\hline Média & 455,9 & 699,8 & 577,9 & - \\
\hline
\end{tabular}

Médias seguidas de letras iguais maiúsculas na coluna e minúsculas na linha iguais não diferem ao teste Tukey a $5 \%$ de probabilidade de erro.

$\mathrm{CV}=$ Coeficiente de variação.

O aumento da massa de colmo no pasto influencia a distribuição de folhas no perfil do dossel e modifica a quantidade e a qualidade da luz no seu interior (FAGUNDES et al., 2005; 2006), o que altera as características morfogênicas e o perfilhamento do pasto. Além disso, com a elevação da massa de colmo, há incremento na produção de forragem, porém a estrutura do pasto é prejudicada devido ao efeito negativo deste componente morfológico sobre o comportamento ingestivo do animal e a eficiência do pastejo.

A elevação da altura de pastejo não influenciou a quantidade de matéria seca do material morto na pastagem (Tabela 3), o qual se manteve constante no decorrer das alturas, independente da estação de crescimento. A taxa de crescimento cultural foi maior nas alturas menores, mas verificou-se para a altura de $45 \mathrm{~cm}$, que houve efeito da estação de crescimento, observando-se 
Rev. Bras. Saúde Prod. Anim., Salvador, v.16, n.1, p.10-22 jan./mar., 2015 http://www.rbspa.ufba.br

maior valor no final da estação, no entanto essa resposta é variável em função da estação de crescimento, verificando efeito significativo da altura somente no final da estação de crescimento (Tabela 4). Independente da altura, o periodo final das chuvas proporcionou maiores valores de TCC, possivelmente em resposta as variáveis ambientais dessa estação (Tabela 1).

Tabela 4. Taxa de Crescimento Cultural (TCC) do capim Piatã manejado sob lotação intermitente com três alturas de entrada durante as estações de crescimento (meio e final da estação)

\begin{tabular}{|c|c|c|c|c|}
\hline \multirow{2}{*}{$\begin{array}{l}\text { Período } \\
\text { Altura }(\mathrm{cm})\end{array}$} & Meio & Final & \multirow{2}{*}{ Média } & \multirow{2}{*}{ CV $(\%)$} \\
\hline & \multicolumn{2}{|c|}{ TCC $\left(\mathrm{Kg}\right.$ ha $\left.\operatorname{dia}^{-1}\right)$} & & \\
\hline 30 & $78,76^{\mathrm{bA}}$ & $133,97^{\mathrm{a} A \mathrm{~B}}$ & 106,36 & - \\
\hline 45 & $82,90^{\mathrm{bA}}$ & $155,05^{\mathrm{aA}}$ & 118,98 & 21,45 \\
\hline 60 & $67,39^{\mathrm{bA}}$ & $112,04^{\mathrm{aB}}$ & 89,72 & - \\
\hline Média & 76,35 & 133,69 & 105,02 & - \\
\hline
\end{tabular}

Médias seguidas de letras iguais maiúsculas na coluna e minúsculas na linha iguais não diferem entre si pelo teste Tukey a $5 \%$ de probabilidade de erro.

$\mathrm{CV}=$ Coeficiente de variação.

Diversos estudos apontam as características estruturais do dossel forrageiro como fator determinante do comportamento ingestivo do ruminante em pastejo, tornando-as bastante importante na interação planta-animal (SANTOS et al., 2009; GOMIDE et al., 2001; CÂNDIDO et al., 2005). A relação folha/colmo é uma dessas características, e essa pode ser bastante influenciada pelo período de descanso e resíduo de pastejo. No presente estudo, as diferentes alturas apresentaram efeito sobre a relação folha/colmo exclusivamente no primeiro período de avaliação, com maiores valores para as alturas maiores e somente para a altura de $30 \mathrm{~cm}$ foi verificado efeito do período de avaliação. Normalmente, as maiores relações $\mathrm{F} / \mathrm{C}$ são observadas em dosséis que tiveram certo controle no alongamento de colmo, e por isso, acredita-se que no meio da estação de crescimento houve melhor controle da estrutura do pasto, possivelmente em função do menor crescimento observado nesse período (Tabela 5).

Tabela 5. Relação dos componentes folha/colmo (F/C) do capim Piatã manejado sob lotação intermitente com três alturas de entrada durante a estação de crescimento (meio e final da estação)

\begin{tabular}{|c|c|c|c|c|}
\hline \multirow{2}{*}{$\begin{array}{l}\text { Período } \\
\text { Altura }(\mathrm{cm})\end{array}$} & Meio & Final & \multirow{2}{*}{ Média } & \multirow[b]{2}{*}{ CV $(\%)$} \\
\hline & \multicolumn{2}{|c|}{ Folha/Colmo } & & \\
\hline 30 & $3,3^{\mathrm{aA}}$ & $2,1^{\mathrm{bA}}$ & 1,79 & - \\
\hline 45 & $2,1^{\mathrm{aAB}}$ & $1,4^{\mathrm{aA}}$ & 1,96 & 36,65 \\
\hline 60 & $2,0^{\mathrm{aB}}$ & $1,8^{\mathrm{aA}}$ & 2,69 & - \\
\hline Média & $2,5^{\mathrm{a}}$ & $1,8^{2 b}$ & - & - \\
\hline
\end{tabular}

Médias seguidas de letras iguais maiúsculas na coluna e minúsculas na linha iguais não diferem entre si pelo teste Tukey a 5\% de probabilidade de erro.

$\mathrm{CV}=$ coeficiente de variação. 
A composição morfológica do capim Piatã foi influenciada tanto pelas estações de crescimento avaliadas quanto pelas alturas de pastejo. Quando analisados os percentuais de lâmina foliar, colmo e material morto todos sofreram ação das diferentes alturas (Tabela 6). Verificou-se que o percentual de colmo apresentou diferença significativa na altura de 30 $\mathrm{cm}$ sendo inferior às alturas de 45 e 60 $\mathrm{cm}$. Este efeito diferencial da estação de crescimento sobre os componentes lâmina foliar, colmo e material morto pode ser atribuído a fatores climáticos que atuam na morfologia das plantas, alterando as relações folha/colmo e material vivo/morto.

Tabela 6. Porcentagem de Lâmina Foliar (PLF), colmo (PCO) e material morto (PMM) do capim Piatã manejado sob lotação intermitente com três alturas de entrada durante a estação de crescimento (meio e final da estação)

\begin{tabular}{|c|c|c|c|c|}
\hline \multirow{2}{*}{$\begin{array}{l}\text { Período } \\
\text { Altura }(\mathrm{cm})\end{array}$} & Meio & Final & \multirow{2}{*}{ Média } & \multirow{2}{*}{ CV (\%) } \\
\hline & \multicolumn{2}{|c|}{ PLF (\%) } & & \\
\hline 30 & $62,47^{\mathrm{aA}}$ & $55,61^{\mathrm{a} A \mathrm{~B}}$ & 59,04 & - \\
\hline 45 & $60,58^{\mathrm{aA}}$ & $47,10^{\mathrm{bB}}$ & 53,84 & 10,52 \\
\hline 60 & $59,33^{\mathrm{aA}}$ & $57,38^{\mathrm{aA}}$ & 58,35 & - \\
\hline Média & 3,85 & 4,60 & - & - \\
\hline \multicolumn{5}{|c|}{ PCO (\%) } \\
\hline 30 & $21,98^{\mathrm{bB}}$ & $27,46^{\mathrm{aB}}$ & 24,72 & - \\
\hline 45 & $28,79^{\mathrm{bA}}$ & $33,78^{\mathrm{aA}}$ & 31,28 & 11,65 \\
\hline 60 & $30,07^{\mathrm{aA}}$ & $31,02^{\mathrm{aAB}}$ & 30,55 & - \\
\hline Média & $26,95^{b}$ & $30,75^{\mathrm{a}}$ & - & - \\
\hline \multicolumn{5}{|c|}{ PMM (\%) } \\
\hline 30 & $15,54^{\mathrm{aA}}$ & $16,93^{\mathrm{a} A \mathrm{~B}}$ & 16,24 & - \\
\hline 45 & $10,63^{\mathrm{bA}}$ & $19,12^{\mathrm{aA}}$ & 14,88 & 28,62 \\
\hline 60 & $10,59^{\mathrm{aA}}$ & $11,60^{\mathrm{aB}}$ & 11,10 & - \\
\hline Média & $15,89^{b}$ & $12,26^{\mathrm{a}}$ & - & - \\
\hline
\end{tabular}

Médias seguidas de letras iguais maiúsculas na coluna e minúsculas na linha iguais não diferem entre si pelo teste Tukey a $5 \%$ de probabilidade de erro.

$\mathrm{CV}=$ coeficiente de variação.

O conceito de índice de área foliar crítico, condição na qual $95 \%$ da luz incidente é interceptada pelo dossel, tem demonstrado ser efetivo e válido para o manejo de gramíneas tropicais, especialmente sob lotação intermitente (CARNEVALLI et al., 2006; BARBOSA et al., 2007; TRINDADE et al., 2007; PEDREIRA et al., 2007; BRAGA et al., 2009). Possivelmente, as plantas com $60 \mathrm{~cm}$ de altura interceptaram luz acima do nível considerado ótimo para definição da condição adequada de manejo.

As mudanças na estrutura e composição do pasto, decorrentes do número de folhas verdes por perfilho e do tamanho final da folha, determinam a quantidade máxima de tecido foliar verde que um perfilho acumula, que, associada ao número de perfilhos por área, contribui para $o$ índice de área foliar. Esta variável é importante para a eficiência de absorção luminosa, a capacidade fotossintética do relvado e, conseqüentemente, para a produtividade da pastagem (LEMAIRE, 1997).

Foi constatada significância da interação altura $\mathrm{x}$ periodo das chuvas sobre o IAF, de modo que os valores de IAF foram superiores no final da estação de crescimento e na altura de 
$60 \mathrm{~cm}$. O número de perfilhos não teve alteração no decorrer das alturas sendo somente observado a superioridade do número de perfilhos no meio da estação de crescimento, como podem ser observados na Tabela 7.

Em pastagens de clima tropical, a densidade da forragem é componente importante da estrutura da forragem que determina a taxa de consumo dos animais em pastejo (HODGSON et al., 1994). Quando tal componente foi avaliado nas alturas observou-se que houve diferença significativa no segundo período de avaliação, onde nas alturas de 45 e 60 foram equivalentes e superiores à altura de pastejo de $30 \mathrm{~cm}$ (Tabela 8). Quando analisado nas estações, verificou-se variação somente para a altura de $30 \mathrm{~cm}$.

Tabela 7. Índice de área foliar (IAF) e número de perfilhos (NP) do capim Piatã no prépastejo manejado sob lotação intermitente com três alturas de entrada durante a estação de crescimento (meio e final da estação)

\begin{tabular}{|c|c|c|c|c|}
\hline Período & Meio & Final & \multirow{2}{*}{ Média } & \multirow{2}{*}{ CV $(\%)$} \\
\hline Altura $(\mathrm{cm})$ & \multicolumn{2}{|c|}{ IAF $\left(\mathrm{m}^{2} / \mathrm{m}^{2}\right)$} & & \\
\hline 30 & $3,40^{\mathrm{bA}}$ & $4,40^{\mathrm{aB}}$ & 3,90 & - \\
\hline 45 & $4,06^{\mathrm{aA}}$ & $3,73^{\mathrm{aB}}$ & 3,89 & 13,38 \\
\hline 60 & $4,08^{\mathrm{bA}}$ & $5,66^{\mathrm{aA}}$ & 4,87 & - \\
\hline Média & 3,85 & 4,60 & 4,22 & - \\
\hline \multicolumn{5}{|c|}{ NP $\left(\right.$ perf $\left.\operatorname{dia}^{-1}\right)$} \\
\hline 30 & 1835,42 & 1308,65 & $1572,03^{\mathrm{A}}$ & - \\
\hline 45 & 1927,97 & 1360,25 & $1644,11^{\mathrm{A}}$ & 12,01 \\
\hline 60 & 1276,15 & 979,79 & $1127,97^{\mathrm{A}}$ & - \\
\hline Média & $1679,85^{\mathrm{a}}$ & $1216,23^{b}$ & 1448,04 & - \\
\hline
\end{tabular}

Médias seguidas de letras iguais maiúsculas na coluna e minúsculas na linha iguais não diferem entre si pelo teste Tukey a $5 \%$ de probabilidade de erro.

Tabela 8. Densidade de forragem $\left(\mathrm{kg} \mathrm{cm} \mathrm{ha}^{-\mathbf{1}}\right)$ do capim Piatã manejado sob lotação intermitente com três alturas de entrada durante duas estações de crescimento (Meio e Final da estação)

\begin{tabular}{lcccc}
\hline Período & \multicolumn{2}{c}{ Meio } & \multirow{2}{*}{ Média } & \multirow{2}{*}{ CV $(\%)$} \\
\cline { 2 - 3 } Altura $(\mathrm{cm})$ & \multicolumn{1}{c}{ Densidade $\left(\mathrm{kg} \mathrm{cm} \mathrm{ha}^{-\mathbf{1}}\right)$} & 100,79 & - \\
\hline 30 & $82,93^{\mathrm{bA}}$ & $118,65^{\mathrm{aB}}$ & 97,56 & 20,72 \\
45 & $93,04^{\mathrm{aA}}$ & $102,08^{\mathrm{aAB}}$ & 78,83 & - \\
60 & $76,95^{\mathrm{aA}}$ & $80,72^{\mathrm{aA}}$ & - & - \\
\hline Média & 84,31 & 100,48 & & \\
\hline \multicolumn{2}{l}{ Médias seguidas de letras iguais maiúsculas na coluna e minúsculas na linha iguais não diferem entre si } \\
\multicolumn{2}{l}{ pelo teste Tukey a 5\% de probabilidade de erro. }
\end{tabular}

A planta quando nova apresenta altos teores de água, quanto mais próximo da sua maturidade esse teor é reduzido e ocorre um aumento nos teores de MS. De acordo com Drudi \& Favoretto (1987) à medida que prolonga o intervalo de corte, o teor de matéria seca de forragem tende a aumentar e seus teores nutricionais são diminuídos.

Em gramíneas tropicais, os constituintes da parede celular dos tecidos, a celulose e a hemicelulose são normalmente a maior fonte de substrato disponível para a fermentação no rumen, e constituem a 
Rev. Bras. Saúde Prod. Anim., Salvador, v.16, n.1, p.10-22 jan./mar., 2015 http://www.rbspa.ufba.br

principal fonte de energia para $o$ ruminante. No entanto, a presença de lignina na parede celular influencia a digestibilidade dessas substâncias (REIS et al., 2005).

O aumento na altura do pasto do capim Piatã, em geral, resultou em variações no FDN e PB, sendo essa resposta influenciada pela estação de avaliação. Em relação ao FDA não foi verificado efeito das fontes de variação (Tabela 9). O FDN foi influenciado pela mudança da estação de crescimento e ainda houve alteração conforme aumentou a altura das plantas. Tal fato corrobora com os estudos de REIS et al., (2005) nos quais verificaram que à medida que a idade fisiológica da planta avança, aumentam as porcentagens de celulose, hemicelulose e lignina, reduzindo a proporção dos nutrientes potencialmente digestíveis (carboidratos solúveis, proteínas, minerais e vitaminas), que pode representar queda na digestibilidade.

Tabela 9. Fibra em detergente neutro (FDN), Fibra em detergente ácido (FDA), Proteína Bruta (PB) do capim Piatã manejado sob lotação intermitente com três alturas de entrada durante as estações de crescimento (meio e final na estação)

\begin{tabular}{|c|c|c|c|c|}
\hline \multirow{2}{*}{$\begin{array}{l}\text { Período } \\
\text { Altura }(\mathrm{cm})\end{array}$} & Meio & Final & \multirow{2}{*}{ Média } & \multirow{2}{*}{$\mathrm{CV}(\%)$} \\
\hline & \multicolumn{2}{|c|}{ FDN (\%) } & & \\
\hline 30 & $56,93^{\mathrm{bC}}$ & $64,08^{\mathrm{aB}}$ & 60,17 & - \\
\hline 45 & $66,32^{\mathrm{aB}}$ & $64,06^{\mathrm{aB}}$ & 65,19 & 3,10 \\
\hline 60 & $69,52^{\mathrm{aA}}$ & $68,81^{\mathrm{aA}}$ & 69,16 & - \\
\hline \multirow[t]{2}{*}{ Média } & 64,26 & 65,65 & 64,95 & - \\
\hline & \multicolumn{2}{|c|}{ FDA $(\%)$} & & \\
\hline 30 & 34,60 & 33,45 & $34,01^{\mathrm{A}}$ & - \\
\hline 45 & 34,45 & 35,10 & $34,80^{\mathrm{A}}$ & 5,03 \\
\hline 60 & 35,23 & 35,98 & $35,59^{\mathrm{A}}$ & - \\
\hline \multirow[t]{2}{*}{ Média } & $34,76^{\mathrm{a}}$ & $34,84^{\mathrm{a}}$ & 34,8 & - \\
\hline & \multicolumn{2}{|c|}{ PB (\%) } & & \\
\hline 30 & $9,43^{\mathrm{aA}}$ & $7,21^{\mathrm{aB}}$ & 8,32 & - \\
\hline 45 & $9,64^{\mathrm{aA}}$ & $12,44^{\mathrm{aA}}$ & 11,04 & 32,26 \\
\hline 60 & $7,98^{\mathrm{aA}}$ & $8,61^{\mathrm{aAB}}$ & 8,29 & - \\
\hline Média & 9,01 & 9,42 & 9,21 & - \\
\hline
\end{tabular}

O estudo mostrou que o manejo das alturas de pastejo exerce importante efeito sobre a produção de forragem. A maior produção de MS foi obtida na maior altura $(60 \mathrm{~cm})$, no entanto, a produção foi compensada quando os dados foram calculados em relação ao número total de ciclos na estação de estudo, onde constatou-se que a altura de 45 e $30 \mathrm{~cm}$ respectivamente, foram superiores à altura de $60 \mathrm{~cm}$.
Verificou-se também, interação entre as estações de avaliação (Meio e final da estação de crescimento) e as alturas de manejo. Em termos qualitativos foram encontradas sensível diferença nos valores de FDN e $\mathrm{PB}$ as quais foram influenciadas pela estação de crescimento avaliada. 
Rev. Bras. Saúde Prod. Anim., Salvador, v.16, n.1, p.10-22 jan./mar., 2015 http://www.rbspa.ufba.br

\section{REFERÊNCIAS}

\section{ALEXANDRINO, E.; NASCIMENTO}

JUNIOR, D.; REGAZZI, A.

Características morfogênicas e

estruturais da Brachiaria brizantha cv.

Marandu submetida a diferentes doses

de nitrogênio e freqüências de cortes.

Acta Scientiarum Agronomy, v.27,

p.17-24, 2005.

BARBOSA, R.A.; NASCIMENTO JR., D.; EUCLIDES, V.P.B. Capim-tanzânia submetido a combinações entre intensidade e freqüência de pastejo.

Pesquisa Agropecuária Brasileira, v.42, n.3, p.329-340, 2007.

BRAGA, G.J.; PEDREIRA, C.G.S.; HERLING, V.R. Eficiência de pastejo de capim-marandu submetido a diferentes ofertas de forragem.

Pesquisa Agropecuária Brasileira, v.49, n.11, p.1641-1649, 2009.

CÂNDIDO, M.J.D.; GOMIDE, C.A.M.; ALEXANDRINO, E.; GOMIDE, J.A.; PEREIRA, W.E. Morfofisiologia do Dossel de Panicummaximum cv. Mombaça sob Lotação Intermitente com Três Períodos de Descanso. Revista Brasileira de Zootecnia, v.34, n.2, p.338-347, 2005.

CARNEVALLI, R.A.; SILVA, S.C. da; BUENO, A.A. de O.; UEBELE, M.C.; HODGSON, J.; SILVA, G.N.; MORAIS, J.P.G. Herbage production and grazing losses in Panicum maximum cv. Mombaça under four grazing managements. Tropical Grasslands, v.40, p.165-176, 2006.

DRUDI, A.; FAVORETTO, V. Influência da freqüência, época e altura de corte na produção e composição química do capim Andropógon.

Pesquisa Agropecuária Brasileira, v.22, n.11, p.1287-1292, 1987.
EMPRESA BRASILEIRA DE PESQUISA AGROPECUÁRIA EMBRAPA. Sistema Brasileiro de Classificação de Solos. Brasilia: Embrapa-SPI / Rio de Janeiro: Embrapa-Solos, 2006. 306 p.

FAGUNDES, J.L.; FONSECA, D.M. MORAIS, R.V.; MISTURA, C.; VITOR, C.M.T.; GOMIDE, J.A.; NASCIMENTO JUNIOR, D.; SANTOS, M.E.R.; LAMBERTUCCI, D.M. Avaliação das características morfogênicas e estruturais do capimbraquiária em pastagem adubada com nitrogênio avaliadas nas quatro estações do ano. Revista Brasileira de Zootecnia, v.35, n.1, p.21-29, 2006.

FAGUNDES, J.L.; FONSECA, D.M.; GOMIDE, J.A.; NASCIMENTO JUNIOR, D.; VITOR, C.M.T.; MORAIS, R.V.; MISTURA, C.; REIS, G.C.; MARTUSCELLO, J.A. Acúmulo de forragem em pastos de Brachiaria decumbens Stapf. adubados com nitrogênio. Pesquisa Agropecuaria Brasileira, v.40, n.4, p.397-403, 2005.

GOMIDE, J.A.; WENDLING, I.J.; BRÁS, S.P.; QUADROS, H.B.

Consumo e produção de leite de vacas mestiças em pastagem de Brachiaria decumbens manejadas sob duas ofertas diárias de forragem. Revista Brasileira de Zootecnia, v.30, n.4, p.1194-1200, 2001 .

GONÇALVES, G.D.; SANTOS, G.T.; CECATO, U. Produção e valor nutritivo degramíneas do gênero Cynodon em diferentes idades ao corte durante o ano. Acta Scientiarum, v.24, n.4, p.11631174, 2002.

HODGSON, J.; CLARK, D.A.; MITCHELL, R.J. Foraging behavior in grazing animals and its impact on plant communities. In: FAHEY, G.C. (Ed.). 
Rev. Bras. Saúde Prod. Anim., Salvador, v.16, n.1, p.10-22 jan./mar., 2015 http://www.rbspa.ufba.br

Forage quality, evaluation and utilization.Lincoln: American Society of Agronomy, 1994. p.796-827.

KÖPPEN, W. Climatologia: com um estúdio de los climas de la tierra. In: CLIMATOLOGY. New Gersey: Laboratory of Climatology, 1948. 104p.

LEMAIRE, G. The physiology of grass growth under grazing: tissue turnover. In: SIMPÓSIO INTERNACIONAL DE PRODUÇÃO ANIMAL EM PASTEJO, 1997, Viçosa, MG: Universidade Federal de Viçosa, 1997. p.117-144.

PEDREIRA, B.C.; PEDREIRA, C.G.S.; SILVA, S.C. da. Estrutura do dossel e acúmulo de forragem de capim-xaraés em resposta a estratégias de pastejo. Pesquisa Agropecuária Brasileira, v.42, p.281-287, 2007.

REIS, R.A.; MELO, G.M.P.; BERTIPAGLIA, L.M.A. Otimização da utilização da forragem disponível através da suplementação estratégica. In: REIS, R.A.; SIQUEIRA, G.R.; BERTIPAGLIA, L.M.A. (Eds.).

Volumosos na produção de ruminantes. Jaboticabal: Funep, 2005. p.187-238.

SANTOS, M.E.R.; FONSECA, D.M.; BALBINO, E.M.; MONNERAT, J.P.I.; SILVA, S.P. Capim-braquiária diferido e adubado com nitrogênio:produção e características da forragem. Revista Brasileira de Zootecnia, v.38, p.650656, 2009.

SILVA, S.C. da; CORSI, M. Manejo do pastejo. In: SIMPÓSIO SOBRE MANEJO DA PASTAGEM, 20., 2003, Piracicaba. Anais... Piracicaba: FEALQ, 2003.p.155-186.
SILVA, T.C. da; MACEDO, C.H.O; ARAUJO, S. dos S.; PINHO, R.M.A.; PERAZZO, A.F.; SANTOS, E,M.; GONZAGA NETO, S. Características agronômicas do capim Brachiaria decumbens submetido a intensidades e frequências de corte e adubação nitrogenada. Revista Brasileira de Saúde e Produção Animal [online], v.12, n.3, p.583 593, 2011.

TRINDADE, J.K.; SILVA, S.C.; SOUZA JÚNIOR, S.J.; GIACOMINI, A.A.; ZEFERINO, C.V.; GUARDA, V.D.A.; CARVALHO, P.C.F.

Composição morfológica da forragem consumida por bovinos de corte durante o rebaixamento do capim-marandu submetido a estratégias de pastejo rotativo. Pesquisa Agropecuária Brasileira, v.42, p.883-890, 2007.

Van SOEST, P.J. Nutritional ecology of the ruminant. 2.ed. Ithaca: Cornell University Press, 1994. 476 p. 8

ZIMMER, A.H.; EUCLIDES, V.P. Importância das Pastagens para o Futuro da Pecuária de Corte no Brasil. In: SIMPÓSIO DE FORRAGICULTURA E PASTAGENS, 1., 2000, Lavras, MG. Anais... Lavras, MG: Universidade Federal de Lavras, 2000. p.1-14.

Data de recebimento: 06/09/2013

Data de aprovação: 29/01/2015 